\title{
Narrativas televisivas y comunidades nacionales: el caso de la telenovela brasileña
}

\author{
Maria Immacolata Vassallo de Lopes* \\ immaco@usp.br
}

\begin{abstract}
Este artículo reflexiona en torno a la importancia de la telenovela brasileña en la cultura e identidad nacional de Brasil. Se concibe a la telenovela como ejemplo de narrativa que impregna la rutina cotidiana de la nación, y que se configura como una experiencia cultural, estética y social. Se analiza la cualidad de la narrativa televisiva como un espacio para aglutinar experiencias públicas y privadas; así, la telenovela se perfila como una forma de narrativa sobre la nación y un modo de participar de esa nación imaginada.
\end{abstract}

This article has reflections about the importance of Brazilian serial TV romantic dramas on both culture and national identity in Brazil. These TV dramas are conceived as an example of a kind of story that impregnates daily routines in the country, and that it becomes as a cultural, aesthetic and social experience. The Tv narrative quality is analyzed as a space for agglutination of public and private experiences. Thus, serial $\mathrm{TV}$ romantic dramas are outlined as a narrative form about the country and a way of participating of that imaginary nation.

\section{INTRODUCCIÓN}

A casi 40 años de su introducción, es posible afirmar que la telenovela ${ }^{1}$ en Brasil conquistó reconocimiento público como pro-

\footnotetext{
*Escola de Comunicaçıes e Artes, Universidade de São Paulo, Brasil.
}

\footnotetext{
${ }^{1}$ Telenovela es el nombre genérico dado a la narrativa ficcional televisiva en Brasil, independientemente de que su formato sea telenovela stricto sensu, miniserie, caso especial u otro. En este artículo, también me referiré a ella como novela que es su nombre más conocido.
} 
ducto artístico y cultural y obtuvo visibilidad como agente central del debate sobre la cultura brasileña y la identidad del país. También puede ser considerada uno de los fenómenos más representativos de la modernidad brasileña, por combinar lo arcaico y lo moderno, por fundir dispositivos narrativos anacrónicos e imaginarios modernos y por tener fuertemente marcada su historia por la dialéctica nacionalización -mass- mediación.

La otra cara de ese proceso fue el progresivo reconocimiento académico de la importancia de la telenovela como objeto privilegiado de estudio sobre la cultura y la sociedad brasileña contemporánea. ${ }^{2}$ Esa peculiar situación alcanzada por la telenovela brasileña es responsable del carácter, si no único, por lo menos muy peculiar, de una narrativa nacional, popular y artística, además de convertirse en tema de estudio consolidado. Este último aspecto no será objeto de este artículo, el cual se propone ofrecer una visión amplia de la importancia alcanzada por la telenovela en la sociedad y en la cultura de Brasil.

\section{LA TELENOVELA EN EL ESCENARIO TELEVISIVO BRASILEÑO}

La fuerte presencia de la televisión en un país situado en la periferia del mundo occidental, podría ser descrita como una paradoja más de una nación que a lo largo de su historia fue representada reiteradamente como una sociedad de contrastes acentuados en-

${ }^{2}$ Los datos muestran un creciente interés por la telenovela por medio de disertaciones de maestría y tesis de doctorado, que pasan de seis en la década del sesenta, a 76 en la del noventa, con un promedio aproximado de ocho trabajos/año. Las tendencias principales en los estudios son: análisis del discurso (abordaje semiótico, estético, intertextualidad, dramaturgia), estudios de recepción (abordaje sociológico, etnográfico), y estudios de producción (sonido, escenografía, autores). El método de investigación más frecuente ha sido el estudio de caso cualitativo de una determinada telenovela o una determinada unidad de recepción (familias, empleadas domésticas, metalúrgicos, jóvenes). Para el presente artículo, todo el levantamiento de datos relativos a la telenovela fue realizado en el centro de documentación del Núcleo de Investigación de Telenovela de la Escuela de Comunicaciones y Artes de la Universidad de São Paulo. 
tre riqueza y pobreza, modernidad y arcaísmo, sur y norte, litoral e interior, campo y ciudad. Y, de hecho, la televisión está implicada en la reproducción de representaciones que perpetúan diversos matices de desigualdad y discriminación. Mas, también es verdad que ella posee una penetración intensa en la sociedad brasileña debido a una capacidad peculiar de alimentar un repertorio común por medio del cual personas de clases sociales, generaciones, sexo, raza y regiones diferentes, se posicionan y se reconocen unas a las otras. Lejos de promover interpretaciones consensuales, antes, produciendo luchas por la interpretación de sentido, ese repertorio compartido está en la base de las representaciones de una comunidad nacional imaginada que la TV capta, expresa y constantemente actualiza. ${ }^{3}$

La televisión ofrece difusión de informaciones accesibles a todos sin distinción de pertenencia social, clase o región. Al hacerlo, ella vuelve disponibles repertorios anteriormente de competencia privilegiada de ciertas instituciones socializadoras tradicionales, como la escuela, la familia, la Iglesia, el partido político, la agencia

${ }^{3}$ B. Anderson (1991) introdujo la noción de "comunidad imaginada" para describir el surgimiento de los Estados nacionales en la Europa del siglo XIX y asocia la consolidación del sentimiento de pertenencia a una comunidad imaginaria al surgimiento de la prensa escrita y de las lenguas nacionales. El ritual de lectura del periódico es señalado como ejemplo de ritual que contribuye a la consolidación de ese sentimiento de comunidad nacional. La noción es útil para entender el significado de las telenovelas en Brasil, en la medida en que el acto de ver esos programas en un determinado horario, diariamente, a lo largo de casi 40 años, constituye un ritual compartido por personas en todo el territorio nacional, que dominan las convenciones narrativas consolidadas por la telenovela y que toman patrones mostrados en ella como referenciales con los cuales definen "tipos ideales" (en el sentido weberiano) de familia brasileña, mujer brasileña, hombre brasileño y también de corrupción brasileña, violencia brasileña, etc. Me parece adecuado usar la noción de comunidad nacional imaginada para referirse a las representaciones sobre Brasil vehiculadas por las novelas, y a las maneras como ellas producen referenciales importantes para la reactualización del concepto de nación y de identidad nacional. En el caso brasileño se trata, como veremos más adelante, del hecho paradójico de que la telenovela, una narrativa ficcional, se haya convertido en Brasil en un espacio público de debate nacional. 
estatal. La televisión disemina la propaganda y orienta el consumo que inspira la formación de identidades (Canclini 1995). En ese sentido, la televisión, y la telenovela en particular, es emblemática del surgimiento de un nuevo espacio público en el cual el control de la formación y de los repertorios disponibles cambió de manos, dejó de ser monopolio de los intelectuales, políticos y gobernantes, de los titulares de los puestos de comando de la sociedad. ${ }^{4}$

Es doblemente contradictorio el hecho de que ese espacio público surja bajo la égida del sector privado donde, no por coincidencia, el producto de mayor popularidad y lucro de la televisión brasileña es la telenovela, y bajo la égida de la vida privada, una vez que la narrativa televisiva ya fue definida como una narrativa por excelencia de la familia. ${ }^{5}$ La novela da visibilidad a ciertos asuntos, comportamientos, productos y no a otros; ella define una cierta pauta que regula las intersecciones entre la vida pública y la privada. ${ }^{6} \mathrm{Si}$ consideramos la telenovela a partir de esas categorías, podemos decir que, durante el periodo de los setenta y ochenta, se estructuró alrededor de representaciones que componían una matriz capaz de sintetizar la formación social brasileña en su movimiento modernizante. Esto puede ser traducido por un casi monopolio de la representación social calcada a partir de las angustias privadas de las familias de clase media de Río de Janeiro y São Paulo. Con la diversificación de la estructura de la televisión (TV por cable, video, mayor competencia) y las modificaciones sociales y políticas en curso en los años noventa (redemocratización política, nuevos movimientos sociales, proceso de globalización), esa fuerza de síntesis del género se des-

${ }^{4}$ J. Meyerowitz (1984) sugiere el desplazamiento de repertorios de esferas restrictas a hombres o mujeres, jóvenes o adultos, como una característica importante de la televisión.

${ }^{5}$ Evocando al intelectual mexicano Carlos Monsiváis, la telenovela sería una narrativa familiar sobre la nación, en la que la guerra es vista como un hecho donde murió un tío, y una ciudad como un lugar donde vive un pariente.

${ }^{6}$ A la telenovela se aplican tanto el concepto de agenda setting como el de forum cultural (Newcomb 1999). 
plaza para nuevas representaciones que cuestionan las anteriores representaciones modernizantes.

\section{LA CONSOLIDACIÓN DE UNA INDUSTRIA TELEVISIVA BRASILEÑA}

Desde los años setenta, por lo menos una característica de la industria cultural brasileña resulta sorprendente por desmentir pronósticos hechos acerca de su inevitable situación de dependencia de la producción cultural de los países más industrializados. La producción de bienes culturales ha presentado un creciente índice de nacionalización a medida que el mercado interno se expande. $\mathrm{Al}$ inicio de la década de los ochenta, cerca de 3/4 de la programación de la Tv ya era nacional y hoy llega a casi el $80 \% .^{7} \mathrm{La}$ nacionalización de la producción se da también en el sector publicitario discográfico, editorial y de historietas, con el cine como la gran excepción. En la producción de telenovela, de los 13 programas de ficción que están actualmente en el aire, nueve (56\%) son nacionales y cuatro (44\%) importados. ${ }^{8}$ Resaltamos que la legislación brasileña sobre la comunicación masiva aún prohíbe el control accionario de grupos económicos extranjeros en los medios de radiodifusión y prensa escrita. ${ }^{9}$

La televisión fue introducida a Brasil en 1950 y, a lo largo de sus 50 años de historia, el Estado influyó de diferentes maneras en esa industria. Él posee hasta hoy el poder de conceder y cancelar concesiones de TV, su política siempre ha sido la de estimular el modelo comercial de TV, no habiendo, en rigor hasta hoy, ninguna experiencia de televisión pública en el país. Además de presentarse como un gran anunciante de los medios de comunicación de masas, el Estado, particularmente a partir de 1964, durante el régimen militar, tornó las telecomunicaciones en un elemento estratégico

\footnotetext{
${ }^{7}$ Según los últimos cálculos, 79\% de la producción de TV Globo es de origen nacional.

${ }^{8}$ Semana del 5 al 10 de noviembre de 2001.

${ }^{9}$ Se encuentra en discusión en el Parlamento un proyecto de ley que permite hasta $30 \%$ de capital extranjero en empresas periodísticas y de radiodifusión.
} 
en las políticas de desarrollo e integración y de seguridad nacional del régimen. Además de aumentar su poder de injerencia en la programación por medio de nuevas reglamentaciones, fuerte censura y políticas normativas, el gobierno militar invirtió intensamente en la infraestructura, lo que posibilitó la formación de redes nacionales (sistema microondas, satélite).

Es sabido que la Red Globo fue la más beneficiada con esas políticas. Creada en 1965, la red creció rápidamente, estimulada por una combinación de diversos factores, como relaciones amistosas con el régimen, sintonía con el incremento del mercado de consumo, un equipo de producción y administración preocupada en optimizar la mercadotecnia y la propaganda, un grupo de creadores de izquierda oriundos del cine y del teatro.

Tras haber crecido en consonancia con otros procesos de cambio estructurales ocurridos en el periodo - la intensa migración del campo a las ciudades (ya en 1970, la población urbana superó a la del campo), la industrialización y la proletarización del trabajo en el campo, el desarrollo de un amplio mercado de consumo (si bien muy concentrado en las clases medias y altas)- la televisión, principalmente por medio de las novelas, capta, expresa y alimenta las angustias y ambivalencias que caracterizaron esos cambios, constituyéndose en vehículo privilegiado del imaginario nacional, capaz de propiciar la expresión de dramas privados en términos públicos y dramas públicos en términos privados.

Es recurrente la movilización de la opinión pública en torno a la curiosidad sobre las verdaderas identidades de los personajes, trazo característico de la estructura melodramática de la novela (nacimiento, carácter, desvíos, etc.) con dramas públicos en términos privados (drogas, sida, trabajo infantil, movimiento de los trabajadores rurales, corrupción política, etcétera.).

Al utilizar una estructura narrativa personalizada y poco definida en términos ideológicos o políticos para tratar de asuntos relativos al espacio público, las novelas levantaron y quizás hayan realmente ayudado a dar el tono a los debates públicos. Se tornaron dos ejemplos históricos tanto la asociación de la novela 
Vale Tudo $(1988)^{10}$ con la elección de Fernando Collor de Melo, que calcó su imagen electoral como "el cazador de rajás", esto es, de destierro de la corrupción económica y política del país, como la influencia de la miniserie Años rebeldes (1992) en el proceso de destitución de ese mismo presidente, tres años después.

Las relaciones entre el Estado y las emisoras de televisión se modifican en la década de los noventa, cuando el fin del régimen militar y la redemocratización del país llevan a la suspensión de las medidas de cercenamiento de expresión y el mercado televisivo se segmenta con la introducción de la Tv por cable y el estímulo de la competencia entre las redes de TV abierta. ${ }^{11}$ La postura de las emisoras es de creciente independencia de gobiernos y partidos políticos y progresivamente basada en mecanismos de mercado regidos por las mediciones de las investigaciones de opinión y audiencia llevadas a cabo por institutos como el IBOPE (Instituto Brasileño de Opinión Pública y Estadística). A través de ellas, los profesionales de mercadotecnia, propaganda y televisión construyen imágenes de la audiencia y sintonizan emisores y receptores, lo que garantiza una dinámica constante de captación y transformación de las representaciones de esos agentes. Telespectadores que se convirtieron en consumidores aun antes que ciudadanos pasan a constituir la unidad de referencia de ese mercado televisivo. ${ }^{12}$ En este interesante aspecto la telenovela también parece funcionar como mediadora, pues puede ser vista a través de un interesante movimiento pendular, tanto como una vitrina de consumo (ropas, utensilios, casas, autos, estilos de vida, en fin), como un panel de temas sociales.

${ }^{10}$ Por economía, todas las telenovelas citadas sin la emisora productora son de TV Globo.

${ }^{11}$ Esos fenómenos están en la base de la caída de audiencia de la Red Globo, mas no al punto de perder su posición de "campeona absoluta de audiencia" (Borelli Priolli 2000). A pesar de la fuerte competencia y aun pérdida de audiencia en ciertos horarios, la situación que todavía prevalece en el panorama televisivo brasileño es el de monopolio de audiencia de la Red Globo, tal es aún la distancia en relación con la segunda red, sBT (Sistema Brasileño de Televisión). El promedio de share de la Globo es de $40 \%$ y el de SBT de $25 \%$.

${ }^{12}$ La relación entre consumo y ciudadanía como nuevo enfoque de estudio, puede ser encontrado en García Canclini (1995). 


\section{ESTRUCTURA DE PRODUCCIÓN Y PALIMPSESTO DE LA} TELENOVELA

\section{Estructura de producción: algunos datos}

La Red Globo de Televisión es parte de las Organizaciones Globo, principal conglomerado de multimedia del país. Ésta posee cerca de ocho mil funcionarios, cubre $99.8 \%$ de las ciudades brasileñas por medio de 113 estaciones afiliadas. A lo largo de su historia, la Globo creó un modelo empresarial de televisión que consiguió vincular orgánicamente la administración, la producción y la comercialización de sus productos. También consiguió consolidar un elenco profesional y un star system bajo contrato exclusivo que, junto con una permanente actualización tecnológica, son responsables del patrón de calidad de sus novelas y del consecuente reconocimiento y fidelidad por parte del público. A partir de 1995 unificó toda su producción de teleficción en la Central Globo de Producción, más conocida como PROJAC (Proyecto Jacarepaguá, barrio de Rio de Janeiro). Ahí trabajan 3,600 personas entre productores, autores, directores, actores, fotógrafos, editores, escenógrafos, iluminadores, sonidistas, estilistas y modelistas. Se concentran los estudios de grabación de todos los programas de ficción, la ciudad escenográfica, los departamentos de construcción de escenarios y vestuarios, de realización de los efectos especiales y del centro de documentación y de registro de imagen. El sistema de producción del PROJAC es normalmente constituido por la grabación simultánea de cuatro novelas, una serie (miniserie o serial) y un especial (producción episódica).

El costo medio de una novela de 180 capítulos es de 15 millones de dólares, lo que equivale a cerca de 80 mil dólares por capítulo. El capítulo diario posee un promedio de 34 escenas grabadas, lo que corresponde a media película de cine. Son 20 horas de grabación y 27 de edición para un capítulo de 45 minutos en el aire. Normalmente, una novela tiene de 60 a $70 \%$ de grabaciones en estudio y de 30 a $40 \%$ en exteriores. La producción emplea un 
promedio de 200 personas y una novela de éxito alcanza alrededor de 45 puntos, un promedio de 32 millones de telespectadores y un share del $58 \% .^{13}$

\section{EL PALIMPSESTO DE LA FICCIÓN EN LA TELEVISIÓN BRASILEÑA ACTUAL}

Como dijimos, la televisión fue introducida en Brasil en 1950, con la extinta tv Tupi de São Paulo. En la televisión abierta existen hoy seis redes nacionales, ${ }^{14} \mathrm{y}$ la disputa por la audiencia se restringe a Globo y SBT, ${ }^{15}$ que son también las únicas que producen ficción doméstica. El prime time de la televisión brasileña fue modelado por Globo ya en la década del setenta y puede resumirse en la secuencia telenoticiario-telenovela-variedades (programa de auditorio, humorístico o game show).

El espacio actual de la ficción televisiva es ocupado por 13 programas, con 10 telenovelas diarias y tres series semanales. Cada capítulo de novela posee en promedio 40 minutos brutos y cada episodio de serie tiene 30 minutos, equivalente a un promedio de siete horas diarias de ficción. De esos 13 programas, Globo participa con ocho, de los cuales siete producciones son nuevas y sólo uno repetido (en el horario vespertino). Globo no vehicula telenovela extranjera, todas sus novelas son nacionales. Por el contrario, su competidor SBT participa apenas con una producción nacional y cuatro importadas (actualmente todas mexicanas).

El horario de la novela fue una creación de Globo desde los años setenta, cuando empezó a producir tres novelas diarias. Ese horario se extiende en una franja que va de las 17:30 a las 22:00 horas. Globo sincronizó el horario de cada novela y acabó por determinar hábitos de audiencia específicos. ${ }^{16}$ La primera franja

${ }^{13}$ Entre las últimas novelas con mayor share están: Laços de Família (2000) 56\%; Porto dos Milagres (2001) 58\%; Terra Nostra (1998) 59\%, y la actual O Clone también con $59 \%$.

${ }^{14}$ Esas redes son: Gobo, SBт, Record, Rede tv!, Bandeirantes y Cultura. Todas son privadas, excepto la última, que es pública.

${ }^{15}$ Ver nota 9.

${ }^{16}$ El telespectador adquiere el hábito de ver, cada día y en una determinada hora, 
es ocupada por Malhação, única soap opera de la TV brasileña dirigida al público infanto-juvenil. Continúa la novela de las seis, generalmente de temática histórica o romántica; la novela de las siete, de tema actual, en clave juvenil y de comedia, y la novela de las ocho, la principal, de tema social y adulto. ${ }^{17}$ Entre la novela de las 6 y la de las 7 sale al aire un telenoticiario regional de 20 minutos, y entre la novela de las 7 y la estelar se trasmite el principal telenoticiario del país con 40 minutos de duración. La lógica que preside ese palimpsesto se tornó clásica por combinar noticiario y melodrama, ficción y realidad, cuya contigüidad ha sido objeto de análisis y de estudios recurrentes.

Hablar de telenovela brasileña es hablar de las novelas de Globo. Son éstas, sin duda, las principales responsables por la especificidad de la tele-ficción brasileña. Esa especificidad es resultado de un conjunto de factores que van, desde el carácter técnico e industrial de la producción, pasando por el nivel estético y artístico y por la preocupación por el texto, hasta converger en el

el mismo programa. El horario de la novela es una institución en la Tv brasileña y suele determinar la hora de la cena y hasta la de dormir. Las clases populares tienen el hábito de dormir "después de la novela de las ocho", que continúa siendo llamada así, a pesar de que actualmente va al aire entre las 9 y las 10 de la noche. Otro hábito creado es ver el principal telenoticiario del país (Jornal Nacional, Globo, 20:15-20:55) que está "emparedado" entre dos novelas. También es común que las personas hagan sus citas nocturnas para "después de la novela". Finalmente, ese horario acabó por configurar también la programación de las demás emisoras, que en el horario de la novela tienen baja audiencia y terminan llevando al aire programas para ser sacrificados, más que verdaderas alternativas a las novelas. La disputa por audiencia en la franja de las novelas de Globo es promovida, en primer lugar, por sBT, única red concurrente de Globo que adoptó la misma lógica de programación exhibiendo en el mismo horario telenovelas, casi todas mexicanas. La segunda competencia a las novelas es promovida por la TV de paga.

${ }^{17}$ Sería necesario otro trabajo para analizar la novela desde el punto de vista de su realización como género y mostrar cómo se fue constituyendo como género híbrido, capaz de fundir en el melodrama otros subgéneros como el cómico, el realismo fantástico, el drama, el romántico. Identificamos en ese género híbrido la base de la teledramaturgia brasileña y uno de los fuertes motivos de la preferencia nacional de la que es objeto la novela. Los otros motivos son la verosimilitud y las temáticas polémicas. 
llamado patrón Globo de calidad. Es posible atribuir a las novelas de Globo el papel de protagonista en la construcción de una teledramaturgia nacional. ${ }^{18}$

La actual parrilla de programación de la ficción televisiva ilustra lo que acabamos de describir.

\begin{tabular}{|c|c|c|c|}
\hline \multicolumn{4}{|c|}{ PARRILLA DE PROGRAMACIÓN DE LA FICCIÓN TELEVISIVA BRASILEÑA* } \\
\hline Emisora & Horario & Telenovela $-45^{\prime}$ & Origen \\
\hline Globo & 14:20 - Lunes a viernes & A Gata Comeu & nacional \\
\hline Globo & 17:35 - Lunes a viernes & Malhação & nacional \\
\hline Globo & 18:05 - Lunes a sábado & A Padroeira & nacional \\
\hline Globo & 19:15 - Lunes a sábado & As Filhas da Mãe & nacional \\
\hline Globo & 20:55 - Lunes a sábado & $\begin{array}{l}\text { O Clone } \\
\text { Serie - 35, }\end{array}$ & nacional \\
\hline Globo & 22:45 - Martes & Brava Gente & nacional \\
\hline Globo & 23:15 - Jueves & A Grande Familia & nacional \\
\hline Globo & 23:05 - Viernes & $\begin{array}{l}\text { Os Normais } \\
\text { Telenovela }-40\end{array}$ & nacional \\
\hline SBT & 17:15 - Lunes a viernes & Preciosa & mexicana \\
\hline SBT & 17:35 - Lunes a viernes & Rosalinda & mexicana \\
\hline SBT & 17:35 - Lunes a viernes & Abraça-me Forte & mexicana \\
\hline SBT & 19:15 - Lunes a sábado & Carinha de Anjo & mexicana \\
\hline SBT & 19:15 - Lunes a sábado & Pícara Sonhadora & nacional \\
\hline
\end{tabular}

${ }^{18}$ La historia de la telenovela comenzó con la primera emisora de Tv, la extinta Tupi, responsable por la novela que fue el marco del brasileñamiento del género, Beto Rockfeller (1968). En años más recientes, la Red Manchete (que quebró en 1999) llegó a construir estudios propios y produjo algunas novelas que en calidad de producción se equipararon a las de Globo. Fueron marcos de su producción: Dona Beja (1986), Pantanal (1990) y Xica da Silva (1996), novelas que provocaron polémica por las escenas de desnudos en sus tramas. Actualmente, SBT constituye la segunda emisora en la producción de telenovelas. Construyó en São Paulo el Proyecto Anhangüera, una enorme área con estudios y locaciones, pero debido a su producción irregular y discontinua, aún no constituye el segundo polo de producción teleficcional del país. 


\section{LA PRODUCCIÓN DE UNA TELEDRAMATURGIA NACIONAL, O "YO VEO EL BRASIL EN LA NOVELA"}

La consolidación de la novela como el género más popular y lucrativo de la televisión, está vinculada a un cambio de lenguaje, saludada por los autores brasileños con trabajo acumulado en la radio y en el cine. La oposición entre novelas "realistas", críticas de la realidad social, cultural y política brasileña, y novelas "fantasiosas", o dramones hechos para hacer llorar, marcó el debate entre los profesionales de la novela, así como la literatura sobre el tema y la opinión de la audiencia. ${ }^{19}$ Más allá de esa oposición, es importante resaltar que aunque la versión "fantasiosa", también conocida como "mexicana", busque mantenerse distante del comentario social y político y no admita el humor, la versión nacional, a pesar de incorporar comentarios sobre asuntos contemporáneos también se rige fuertemente por los orígenes folletinescos del género.

A partir de finales de los años sesenta y siguiendo el modelo propuesto por la Red Tupi, ${ }^{20}$ las novelas de la Red Globo se contrapusieron al estilo "fantasioso" que dominaba la producción anterior, proponiendo una alternativa "realista" (Ortiz 1989; Mattelart y Mattelart 1989). La ruptura con el modelo representado por la novela Sheik de Agadir (Globo 1966), con sus personajes de nombres extranjeros viviendo dramas pesados, diálogos formales y vestuarios pomposos, ambientados en tiempos y lugares remotos, para el paradigma de la novela brasileña, lo marcó la novela Beto Rockfeller (Tupi 1968). Este paradigma trajo la trama para el universo contemporáneo de las grandes ciudades brasileñas, el uso de grabaciones externas, introdujo el lenguaje co-

${ }^{19}$ Según investigación reciente, $68 \%$ de los telespectadores nunca ven novelas producidas en países latinoamericanos, como México y Colombia (investigación TGI - Target Group Index, octubre de 2001).

${ }^{20}$ La Red Tupi fue la primera red de televisión de Brasil; marcó época como pionera en los caminos de una dramaturgia propia de la televisión y sobre la base de temas y personajes brasileños. Con su quiebra en los años setenta se inicia la hegemonía de Globo. 
loquial, el humor inteligente, una cierta ambigüedad de los personajes y, principalmente, referencias compartidas por los brasileños. Sintonizó las ansiedades liberales de un público joven, tanto masculino como femenino, recién llegado a la metrópoli, en busca de instrucción e integración en los polos de modernización. Las convenciones que pasaron a ser adoptadas a partir de entonces se basan en que cada novela debería traer una "novedad", un asunto que la diferenciara de sus antecesoras y fuese capaz de "provocar" el interés, el comentario, el debate de telespectadores y de los otros medios, el consumo de productos relacionados con ella, como libros, discos, ropas, etc. Ese énfasis en la representación de una contemporaneidad sucesivamente actualizada es visible en la moda, en las tecnologías, en las referencias a acontecimientos corrientes. Mas es visible también en la evolución en la manera como el amor, el sentimiento, el romance y la relación hombre-mujer fueron representados en las novelas de los años setenta en adelante.

Esa opción por una definición clara en el tiempo y en el espacio -casi siempre la coyuntura contemporánea situada en el ámbito de la nación- potencia la vocación de la novela de mimetizar y de renovar constantemente las imágenes de lo cotidiano de un Brasil que se "moderniza". Eso puede ser identificado a través de los dos planos estructurales de toda novela: el renovado sentido de explotación de temas contemporáneos y el verdadero "efecto-demostración" de los patrones de consumo vividos por los personajes que hacen señas para la población de espectadores con la posibilidad concreta de integración social por medio del consumo. Esa casi obsesión por la coyuntura y la moda es acomodada a la estructura seriada e interactiva del folletín y moviliza repetidamente el género melodramático como matriz cultural y dispositivo de comunicabilidad (Martín-Barbero 1987). La trama de las novelas es producida generalmente por oposiciones entre hombres y mujeres; entre generaciones; entre clases sociales; entre localidades rurales y urbanas, "arcaicas" y "modernas", representadas como tendencias intrínsecas y simultáneas de la contemporaneidad brasileña. Otros recursos dramáticos típicos como iden- 
tidades falsas, intercambio de hijos, padres desconocidos, herencias repentinas, ascensión social vía matrimonio, están presentes de manera recurrente y conviven bien con referencias a temáticas y repertorios nacionales y actuales en la época en que salen al aire.

Elevada a la posición de principal producto de una industria televisiva de grandes proporciones, la novela pasó a ser uno de los más importantes y amplios espacios de problematización de Brasil, de las intimidades privadas a las públicas. Esa capacidad sui generis de sintetizar lo público y lo privado, lo político y lo doméstico, la noticia y la ficción, lo masculino y lo femenino, está inscrita en el texto de las novelas que combinan convenciones formales del documental y del melodrama televisivo. Eso es lo que, a nuestro entender, más tipifica a la telenovela brasileña y constituye la paradoja de identificar a Brasil más en una narrativa ficcional que en un telenoticiario. Son recurrentes en las novelas la identificación entre personajes de ficción y figuras públicas reales, entre las tramas y los problemas reales y la tendencia hacia una mayor verosimilitud en las historias contadas; esta última además, una demanda fuerte del propio público. ${ }^{21}$ Tal combinación de géneros e informaciones puede ser encontrada, por ejemplo, en el uso de documentales de época insertos en las secuencias de las novelas ya desde Irmãos Coragem (1970, novela de tiempo actual) hasta Terra Nostra (1998, novela de época). Además se puede mencionar la más reciente "invasión" de la realidad en la novela Porto dos Milagres (2001) por el uso, en el intervalo comercial, de clips de campaña electoral con los personajes de la novela, provocando el efecto de realidad de una propaganda hecha por partidos políticos verdaderos. Y, finalmente, la incorporación del noticiario, llevada a las últimas consecuencias que pasó a

${ }^{21}$ Son comunes las críticas tanto de los medios como del público a ciertas situaciones tratadas en una novela como siendo irreales y fantasiosas, demandando más realidad y menos ficción. Esa tendencia al realismo, o más precisamente, a una naturalización de las historias contadas en las telenovelas, tal vez esté en la base de los mecanismos de legitimación y de credibilidad de las novelas en Brasil. Sobre las relaciones entre ficción y realidad en la telenovela brasileña, ver los trabajos de Lopes et al. (2002) y de Motter (2001). 
ser denominado de merchandising social (Schiavo 1995) en novelas recientes como la divulgación del trabajo de las ong y la presencia de madres de niños desaparecidos (Explode Coração 1995), el movimiento de los Sin Tierra y la presencia de dos senadores de la república en el velorio del senador de la ficción $(O R e i$ do Gado 1996), la donación de órganos y la presencia de médicos explicando el cáncer de una joven (Laços de Família 2000).

\section{LA TELENOVELA COMO OBRA ABIERTA Y OBRA DE AUTOR}

Fruto de la combinación de profesionales de posiciones e intenciones diversificadas, de dramaturgos y escritores de izquierda, pasando por actores de talento a productores y publicitarios con visión de industria y mercado, las novelas pasaron a constituir el principal producto de la Red Globo que, además la ayudaron a proyectarse como el mayor conglomerado brasileño de medios, y competitivo en el ámbito internacional. ${ }^{22}$ Por lo menos desde los años setenta, a través de Globo se ha consolidado una serie de mecanismos de producción y convenciones de escritura y de recepción que configuran un sistema de real retroalimentación en la producción de un producto masivo. Ese sistema toma en cuenta la participación de los telespectadores en el momento mismo de la producción. En ese sentido, y porque salen al aire en cuanto están siendo escritas, las novelas fueron definidas como obras abiertas (en el sentido de Umberto Eco). Éstas son capaces de poner en sintonía a los telespectadores con la interpretación y la reinterpretación de los temas tratados.

La novela se convirtió en un vehículo que capta y expresa la opinión pública sobre patrones legítimos e ilegítimos de compor-

${ }^{22}$ El carácter de monopolio de la televisión brasileña ejercido por la Red Globo es indiscutible hasta hoy. Eso aun con la guerra de audiencia promovida por la segunda red, SBT, trabada en algunos segmentos de horario, principalmente en programas de auditorio comandados por su propietario, Silvio Santos, quien tiene una trayectoria muy peculiar de self made man, de vendedor ambulante a empresario y dueño del segundo conglomerado de medios en el país. 
tamiento privado y público, produciendo una especie de forum de debates sobre el país. Son innumerables los aspectos con los que se manifiesta la construcción de esa obra abierta, los cuales se dan a partir de la selección del tema de la novela en forma de sinopsis presentada por el autor (guionista), revelando una mayor o menor sensibilidad y afinidad con las demandas embrionarias o explícitas del público. Éste es el primer aspecto a ser evaluado en términos de posibilidad de que la novela lo "recoja" en forma de audiencia.

Los autores de novela son nacionalmente conocidos por los temas a los que se dedican, de modo que cuando se anuncia la próxima novela en la campaña de lanzamiento, el nombre del autor es destacado ("novela de Benedito Rui Barbosa") como procedimiento de identificación del universo ficcional de ese autor. Y lo que se espera pasa a ser materia de comentarios en periódicos, revistas, emisoras de radio y televisión, y tal vez más importante, pasa a ser conversado anticipadamente por las personas. ${ }^{23}$ Otro aspecto es la convención de que la novela salga al aire solamente cuando 25 capítulos fueron grabados, lo que, según la producción, es un promedio suficiente para que el trabajo de las grabaciones sea hecho al sabor de los cambios que se van haciendo en el guión. La producción también incorpora los indicadores proporcionados por la realización permanente de grupos de discusión organizados por el sector de investigación de Globo. Pero todo se dirige a dar cada vez más peso al juego de la interacción entre la novela y el públi-

${ }^{23}$ Los escritores de novelas son llamados significativamente autores y no guionistas. Cada autor tiene un equipo de dos a tres escritores para desarrollar una novela que tiene en promedio 180 capítulos. Cada autor es conocido por su universo temático y por la composición de los personajes. Algunos llegan incluso a autorreferenciarse cuando en una novela el autor remite a personajes, lugares y situaciones desarrolladas por él en otra. Así, Benedito Rui Barbosa es conocido como autor que trabaja con la temática rural; Aguinaldo Silva con la temática femenina y racial; Gilberto Braga es el cronista de la clase media carioca; Manoel Carlos retrata lo cotidiano de la vida de las grandes ciudades; Silvio de Abreu hace novelas de humor con remesas cinematográficas; Lauro Cesar Muñiz se dedica al tratamiento social crítico; Gloria Perez, a las innovaciones de contenido polémico, etcétera. 
co, la movilización de la empatía por los contenidos temáticos, formales y estéticos, donde todo cuenta: la apertura, la historia central, las tramas paralelas, los actores, los escenarios, las músicas, los vestuarios y cuya evaluación es cotidiana, se expresa cuantitativamente en los índices de audiencia, pero sobre todo en los circuitos de la circulación de las conversaciones, de los cuales hablaremos más adelante. Éstas, además de evidenciar una poderosa red de producción y circulación de sentido, expresan la verdadera recepción. Tenemos, por tanto, una captación cuantitativa y formal de la recepción dada por los índices de audiencia y una captación cualitativa e informal de la recepción a través de su red de circulación.

\section{TEMAS DE LA VIDA PÚBLICA Y DE LA VIDA PRIVADA}

Eventos y temáticas sociales y políticas remiten a la ya citada discusión sobre el carácter crítico de las novelas y las referencias explícitas a la nación.

Avanzamos con la hipótesis de que la novela ejerce la función de agenda setting; tal es la agenda temática tratada. Cuestiones como la reforma agraria, el coronelismo (el poder de las oligarquías locales), la especulación inmobiliaria, las compañías multinacionales, la corrupción política, el racismo, las minorías, entre otras, son algunos ejemplos de esa vocación de las novelas por incorporar temas del ámbito público en sus narrativas teóricamente dirigidas al universo privado. Mas temáticas como ésas en las novelas son inseparables de las temáticas del romance, de la familia, del amor, del matrimonio, de la separación. La lógica de las relaciones personales, familiares preside la narrativa de los problemas sociales. Y ahí parece residir el poder de esa narrativa, traducir el público por medio de las relaciones afectivas, en el ámbito de lo vivido, mezclándose con la experiencia del día a día, que es vivida en múltiples facetas, subjetiva, emotiva, política, cultural, estética, etcétera.

La fusión de los dominios de lo público y de lo privado realizada por las novelas les permite sintetizar problemáticas amplias 
en figuras y tramas puntuales y, al mismo tiempo, sugerir que dramas personales y puntuales lleguen a tener significado amplio. En ese sentido, son ejemplares los casos de la novela Barriga de Aluguel (1990), que cuenta la historia de una inseminación artificial; de trasplante de corazón en De Corpo e Alma (1992); de la destrucción del medio ambiente en Mujeres de Arena (1993); de la llegada de la Internet en Explode Coração (1995); de la violencia urbana en A próxima Vítima (1995) y en Torre de Babel (1998), y del actual $O$ Clone (2001), con la clonación humana.

Sin embargo, tal vez es en la trayectoria de los personajes femeninos, así como en la de las representaciones del amor y de la sensualidad, donde se expresa de mejor manera esa capacidad de aglutinar experiencias públicas y privadas que caracteriza a las novelas.

La primera novela, aún no diaria, de la televisión brasileña, Sua Vida me Pertence (Tupi 1951), llamó la atención por un beso ardiente. Al comienzo de los años setenta, el beso todavía encarnaba la sensualidad máxima en las novelas. Pero, a lo largo de esa década el ritmo de las transformaciones en la manera como las novelas representaron los tipos ideales de mujer, de relaciones amorosas y de estructura familiar, se aceleró. El privilegio del beso sería rápidamente sustituido por una liberalización creciente de las novelas, que se adentraron en los aposentos íntimos de los personajes: escenarios de cuarto, parejas en la cama y gestos que simbolizan el orgasmo pasaron a ser admitidos. Jugando con el universo prohibido del incesto, de la prostitución, del placer, de la desnudez, del sexo antes del matrimonio, desvinculándolo de la procreación, de la separación como salida para matrimonios infelices, legitimando la formación de una segunda pareja. Más aún, se pasó a tratar de la vida profesional e independencia financiera de la mujer, ${ }^{24}$ de las tecnologías reproductivas (Barriga de Aluguel 1990; O Clone 2001), de la constitución de nuevos acuerdos fa-

${ }^{24}$ En la novela Laços de Familia (2000), este tema fue tratado en forma de comedia, en la cual la superioridad profesional y financiera de la esposa fue causa de la impotencia sexual del marido. 
miliares en los que una mujer, aunque soltera, decide criar hijos concebidos en relaciones diferentes (Laços de Família 2000). Entran en escena y son cada vez más constantes los matrimonios interraciales (Corpo a Corpo 1984; A Próxima Vítima 1995; A Indomada 1996; Por amor 1997; Suave Veneno 1999; Laços de Família 2000; Porto dos Milagres 2001) y parejas de homosexuales, sea entre hombres jóvenes y adultos como entre mujeres (Vale Tudo 1985; A Próxima Vítima 1995; Por amor 1997; Torre de Babel, 1998). ${ }^{25}$ Otro indicador de la ampliación del espectro de los patrones modernos de comportamiento legitimados por las novelas es la introducción de romances entre mujeres con hombres más jóvenes, así como del amor en la tercera edad y un modelo de mujer profesional, liberada e independiente, captando y expresando representaciones que casi siempre son más avanzadas en relación con la realidad vivida. La recurrencia con que los patrones desviantes del matrimonio y de la sexualidad son tratados en las novelas hace que éstas pasen a dar enorme visibilidad pública a la discusión de esos temas antes tratados sólo en el ámbito privado. Y, aún más importante, el tratamiento realista dado a esos temas no suele escamotear los elementos de conflicto y de preconcepto, lo que otorga a la novela alta credibilidad para el público. Es mediante ese efecto de credibilidad de las novelas que éstas ponen en circulación y debate mensajes sobre la tolerancia y el derecho a la diferencia, a pesar del casi siempre "final feliz" dado a esas historias. Y tal vez la fascinación y la repercusión pública de las novelas estén relacionadas con esas osadías en el enfoque de los dramas comunes de cada día. En qué medida la moraleja corresponde a modelos convencionales o liberales, tiene que ver con una negociación simbólica o de los significados en juego, negociación llena de mediaciones que involucra autores, productores, investigadores de mercado, instituciones como la

${ }^{25}$ Hay que mencionar que en la novela Torre de Babel (1998), una pareja de lesbianas fue retirada de la historia por provocar intensas manifestaciones negativas, principalmente en los medios. Se hizo famosa la solución dada por el autor de la novela, al explotar el aspecto en el que ellas (bellas, liberadas y exitosas) eran empresarias de moda. 
censura, la Iglesia, los movimientos negro, feminista, gay, onG y los diferentes públicos que ven novelas. Cierto es que esos dramas ya no son lineales ni unilaterales, sino bastante difusos y marcados por un movimiento ambivalente entre transgresión y conformismo. Con relación al asunto de la discriminación racial y sexista, el tratamiento viene siendo crecientemente informativo, antidogmático y a favor de la tolerancia y del respeto a las llamadas minorías. En este aspecto, la novela parece configurarse como una línea de fuerza en la construcción de una sociedad multicultural en Brasil.

\section{PACTO DE RECEPCIÓN Y TERRITORIOS DE CIRCULACIÓN DE SENTIDOS}

No hay duda de que la novela constituye un ejemplo de narrativa que sobrepasó la dimensión de la distracción que impregna la rutina cotidiana de la nación, que construyó mecanismos de interactividad y una dialéctica entre el tiempo vivido y el tiempo narrado y que se configura como una experiencia, al mismo tiempo, cultural, estética y social. Como experiencia de sociabilidad, ella acciona mecanismos de conversación, del compartir y de participación imaginaria.

La novela se tornó una forma de narrativa sobre la nación y un modo de participar de esa nación imaginada. Los telespectadores se sienten participantes de las novelas y movilizan informaciones que circulan en torno a ellos en su vida cotidiana. ${ }^{26}$

\footnotetext{
${ }^{26}$ A partir de mediados de la década de los ochenta, ante la insatisfacción con los trabajos que se restringían a interpretar el contenido ideológico de programas televisivos, o priorizaban el análisis político-institucional de la industria cultural, el foco de los estudios pasó a recaer en la recepción. El análisis de esos estudios extrapola los objetivos del presente texto. Nos limitamos solamente a resaltar que la trayectoria de esos estudios fue marcada por una ampliación de las referencias teóricas y de los cuadros metodológicos, en los que se pasó a adoptar un enfoque crecientemente complejo e interdisciplinario a tal punto que la recepción no fue ya tratada como un polo, aunque activo, del proceso de comunicación, como aparece en la gran literatura internacional sobre el tema. En los actuales estudios latinoamericanos, la recepción aparece propia-
} 
Las relaciones del público con las novelas son mediadas por una variedad de instituciones, investigaciones de audiencia, relaciones personales, contactos directos con autores, además de la prensa escrita y de los medios especializados.

Tan importante como el ritual de ver cotidianamente los capítulos de las novelas son la información y los comentarios que llegan a todos, aun a aquellos que sólo de vez en cuando o raramente ven la novela. Las personas, independientemente de clase, sexo, edad o región, acaban participando del territorio de circulación de los sentidos de las novelas, formado por innumerables circuitos donde son reelaborados e resemantizados. La novela es tan vista como hablada y sus significados son producto tanto de la narrativa audiovisual producida por la televisión como de la interminable narrativa oral producida por las personas. Como muchas investigaciones ya lo mostraron, la novela comienza a ser comentada durante el propio acto de su audiencia. Se conversa sobre ella en casa, con el marido, la madre, los hijos, la empleada,

mente como una perspectiva de análisis por la cual todo el proceso de comunicación es reconstituido (producción, medio, texto y público). Parece que el término "recepción" ya no alcanza más para dar cuenta de ese tipo de investigación, la que preferimos llamar de estudio de mediaciones. A nuestro entender, son éstos los que pasan a ser una marca distintiva de las actuales investigaciones latinoamericanas de comunicación. Esos estudios en Brasil comenzaron discutiendo las diferencias de interpretación entre segmentos determinados del público, como la clase social y la situación geográfica hasta llegar a los estudios más actuales que demuestran el carácter interactivo de la novela, de la construcción de un repertorio compartido sobre la nación, del pacto de recepción entre la producción y el público, en una dinámica que a lo largo de los años consolidó convenciones formales de narrativa que son de amplio dominio del público. Las diferencias de interpretación de las novelas en las diferentes regiones, clases y segmentos sociales, sólo son posibles porque todos ven la novela. Como lo dijimos al inicio del presente texto, el significado sociocultural de la telenovela en Brasil (y en el resto de América Latina) para la modernidad que se vive en la región, va mucho más allá que el de sus efectos. Y aquí parecen adecuadas las fértiles pistas abiertas por estudios sobre las relaciones entre oralidad y visualidad, que ven la televisión y particularmente la telenovela, como dispositivos de reordenamiento de la cultura (Martín-Barbero y Rey 1999). 
con los vecinos, los amigos, en el trabajo. Se habla de ella en las revistas especializadas en comentarios y chismes sobre novelas; en columnas de los periódicos diarios, tanto los de prestigio como los populares; en las investigaciones de opinión realizadas por institutos; en las cartas de lectores mandadas a los periódicos y revistas; en los programas de televisión y radio que siguen las novelas tanto en forma de reportaje y entrevistas con sus actores, como en programas de humor donde son satirizadas. La novela también aparece en la música de CDs de bandas sonoras que son especialmente compuestas; en todo un circuito de merchandising que va desde las ropas y joyas usadas por los actores, hasta los objetos de decoración, bebidas, carros, tiendas y bancos que aparecen en las historias; en los comerciales con los actores de las novelas que están al aire.

Los autores declaran expresamente a la prensa que buscan personas en la calle para saber sus opiniones sobre lo que están escribiendo, para así tener ideas sobre el desarrollo de los personajes. Las jergas y manierismos usados por ciertos personajes son incorporados rápidamente en el lenguaje del día a día; nombres de personajes se ponen de moda y niños son bautizados con ellos; nombres de novelas pasan a ser nombres de panaderías y tiendas; también nombres de ciertos personajes son usados como adjetivos para designar el carácter desviante de personas.

Además de eso, situaciones vividas por un personaje en la novela o las características de su carácter pueden ser objeto de movilización de sindicatos, del movimiento negro o gay, de políticos, de comunidades étnicas que critican o reivindican cambios en situaciones, y personajes que contradicen su imagen pública. ${ }^{27}$ Las novelas incluso pueden reflejarse en las propuestas de proyectos de ley para el establecimiento de cuotas de actores negros

${ }^{27}$ Las manifestaciones públicas casi siempre van en el sentido de criticar a las novelas por discriminación (por el tratamiento indebido a personajes negros, gays, mujeres, niños), por difamación (por ejemplo, políticos o figuras públicas que se sienten aludidas), por realzar trazos negativos de categorías profesionales (como policías, abogados, médicos, periodistas, empresarios de multinacionales, etcétera). 
y en la reglamentación del trabajo de actores infantiles y adolescentes. Con frecuencia, las tramas de las novelas provocan la discusión sobre la necesidad de códigos de ética por parte de las emisoras de TV, sea en forma de ley o de autorreglamentación.

Por último, las novelas provocan la simpatía por personajes que se encuentran en conflicto, sobre lo que ellos deben hacer, o sobre el cambio que debe realizarse en su comportamiento. El espacio más nuevo ocupado por toda esa conversación que la novela provoca, es la Internet, donde cada novela tiene su sitio Web (informado al final de los créditos que cierran cada capítulo diario), y las opiniones se expresan en innumerables listas de discusión. ${ }^{28}$

La fuerza y la repercusión de la novela moviliza cotidianamente una verdadera red de comunicación, a través de la cual se da la circulación de sus sentidos y provoca la discusión y la polémica nacional. Mediante ese forum de debates capilarmente difuso, complejo y diversificado, las personas sintetizan experiencias públicas y privadas, expresan divergencias y convergencias de opinión sobre acciones de personajes y desdoblamientos de historias. El carácter de repertorio compartido permite la manifestación de diferencias, la expresión de las competencias sobre el género, de dominio de las convenciones dramatúrgicas de la telenovela, de la sensibilidad del mirar de cerca los detalles, sea en los escenarios y en los vestuarios, sea en los múltiples plots que se entrelazan en el enmarañado de 200 capítulos para, al final, emitir su juicio sobre diversos finales de esas tramas. Se critica o se aplaude la producción por la conducción de la obra.

Cuando una novela galvaniza el país, en ese momento actualiza su potencial de sintetizar el imaginario de una nación, esto es, su identidad, o lo que es lo mismo, de expresarse como nación imaginada. Esta representación, aunque estructuralmente melodramática y sujeta a la variedad de interpretaciones, es aceptada como verosímil, vista y apropiada como legítima y objeto de

${ }^{28}$ Como ejemplo de este foro reciente, un periódico promovió una discusión basada en un reportaje en el que se identificaba el "blanqueamiento" de los personajes en una telenovela reciente, Porto dos Milagres (2001), adaptación de la novela de Jorge Amado cuyos personajes son mayoritariamente negros. 
credibilidad. Existe un consenso en la literatura en denominar ese imaginario como moderno, ya que las novelas promueven los imaginarios modernos de la nación sobre algunos ejes temáticos recurrentes y que, en síntesis son: la movilidad social, la nueva familia, la diversidad sexual, étnica, racial, la afirmación femenina, la renovación ética.

Es por lo menos irónico que un programa inicialmente clasificado por la industria como entretenimiento dirigido a las mujeres de clase "C", haya dominado el horario noble de la televisión brasileña y se haya transformado en un foro de debates sobre la nación compartido por un público compuesto por mujeres, hombres y niños en todos los grupos sociales y locales del territorio nacional. La novela tal vez representa el único ejemplo de cómo un sistema de medios televisivo puede ser responsable del surgimiento de un espacio peculiar que en los años actuales se ha diversificado y se presenta como alternativa principal de realización personal, incluso social y de poder, es decir, como una forma de ciudadanía. La novela, en fin, logró permear el espacio público brasileño a la actualización y a la problematización de la identidad nacional en un periodo de profundas y aceleradas transformaciones.

\section{UNA BREVE CONCLUSIÓN: LA TELENOVELA BRASILEÑA, DEL ESPACIO AUDIOVISUAL NACIONAL AL TRANSNACIONAL}

Como vimos, lo que tornó a la telenovela un enclave estratégico para la producción audiovisual brasileña, es tanto su peso en el mercado televisivo como también el papel que ejerce en la producción de las imágenes que los brasileños se hacen de sí mismos, y a través de las cuales se reconocen. Tan sólo ese hecho es suficiente para volver indispensable la reflexión sobre los diferentes sentidos de la telenovela en el plano nacional. Es éste el objetivo que produjo el presente artículo. Sin embargo, no queremos concluirlo sin dejar de, por lo menos, señalar y reconocer también su importancia regional y transnacional. 
Estructurada en Brasil, y también en América Latina, entre los años sesenta y setenta, la telenovela fue un factor determinante en la creación de una capacidad televisiva que se proyectó no sólo en una extensa producción sino también en una particular apropiación del género, esto es, su nacionalización. Entre tanto, eso va más allá de modelar el carácter nacional de la telenovela. Están involucradas dos dinámicas diferentes muy íntimamente conectadas: una de ellas impulsa la integración del espacio latinoamericano y otra moviliza el mercado mundial. Dentro de América Latina, la telenovela cuenta con la ventaja de un largo proceso de identificación masiva y popular, puesta en movimiento desde los cuarenta y cincuenta, resultando en lo que se podría llamar un proceso de integración sentimental de los países latinoamericanos - una estandarización de modos de sentir y de expresar, de gestos y sonidos, ritmos de danza y de cadencias narrativas- hecho posible por las industrias culturales de la radio y del cine (Martín-Barbero y Rey 1999). Esto quiere decir que, en tanto marco en esta dinámica de integración -los países en su pluralidad nacional y diversidad cultural- la telenovela es también el lugar de intervención de la dinámica de la globalización del mercado mundial. La internacionalización de la telenovela responde al movimiento de activación y reconocimiento de lo que es específicamente latinoamericano en un género televisivo que comienza a exportar éxitos nacionales.

En forma contradictoria, su internacionalización también responde al movimiento de progresiva neutralización de las características de una latinoamericanidad en un género que la lógica del mercado mundial pretende convertir en transnacional en el momento de su producción. Las coproducciones son recientes en América Latina. En cuanto Globo se asocia con Telemundo, segunda red hispánica de Estados Unidos y brazo de la Sony Pictures Entertainment para realizar coproducciones destinadas exclusivamente al mercado externo, SBT también intenta coproducir con la Univisión de Estados Unidos, asociada de la mexicana Televisa. En este aspecto, Brasil hizo historia con la exportación de 
telenovelas por Globo que alcanzaron índices notables de audiencia en gran cantidad de países de Europa y Asia -casos de $A$ Escrava Isaura, Dancing Days, Roque Santeir o, hasta la reciente Terra Nostra - Por otro lado, Televisa de México, concentrada más en América Latina y en la audiencia hispana de Estados Unidos, también alcanzó enorme éxito con Los ricos también lloran y con Simplemente María.

En Europa, en años recientes, el reordenamiento de los sistemas nacionales de televisión europea, la privatización y la expansión de canales y la introducción del sistema por cable y satélite, ampliaron enormemente la programación y abrieron el mercado a la internacionalización de telenovelas de otros países latinoamericanos como Venezuela, Argentina y Perú. La entrada de las telenovelas latinoamericanas en el mercado audiovisual mundial ciertamente muestra el nivel de desarrollo alcanzado por la industria de la televisión en esos países y también significa, en alguna medida, el rompimiento de la línea demarcatoria entre norte y sur en cuanto a los países considerados productores y los considerados exclusivamente consumidores (Buonanno 1999).

Éstos son desafíos que se colocan en un mercado televisivo hegemonizado, pero también fragmentado y segmentado en su consumo y complejizado por la aparición de nuevos actores sociales y de nuevas identidades colectivas. Desafíos en los que conviven procesos ambivalentes como la tendencia a disolver las diferencias culturales y a la indiferenciación de las audiencias, por un lado y, por otro, la tendencia a la migración y a la afirmación en otros territorios de géneros nacionales, como la telenovela brasileña. 


\section{REFERENCIAS BIBLIOGRÁFICAS}

Anderson, Benedict (1991) Imagined communities. Londres: Verso.

Borelli, Silvia, y Gabriel Priolli (coords.) (2000) A deusa ferida. São Paulo: Summus.

Buonanno, Milly (1999) El drama televisivo. Barcelona: Gedisa.

García Canclini, Néstor (1995) Consumidores e cidadãos. Río de Janeiro: UFRJ. Lopes, Maria Immacolata Vassallo, et al. (2002) Vivendo com a telenovela recepção, mediações e ficcionalidade. São Paulo: Summus.

Martín-BARBero, Jesús (1987) De los medios a las mediaciones. Barcelona:

Gustavo Gili.

__ , y Germán Rey (1999) Los ejercicios del ver. Barcelona: Gedisa.

MatTelart, Armand, y Michèle Mattelart (1989) O carnaval das imagens. São Paulo: Brasiliense.

MeYerowitz, Joshua (1984) No sense of place. Oxford: University Press.

MotTer, Maria Lourdes (2001) "A telenovela: documento histórico e lugar de memória”, Revista uSP, núm. 48. São Paulo: usP/CCS.

Newcomв, Horace (1999) La televisione da forum a biblioteca. Milán: Sansoni.

Ortiz, Renato, et al. (1989) Telenovela: história e produçao. São Paulo: Brasiliense.

Schiavo, Marcio (1995) Merchandising social: uma estratégia sócio-educacional para grandes audiências. Río de Janeiro: Un Gama Filho. 